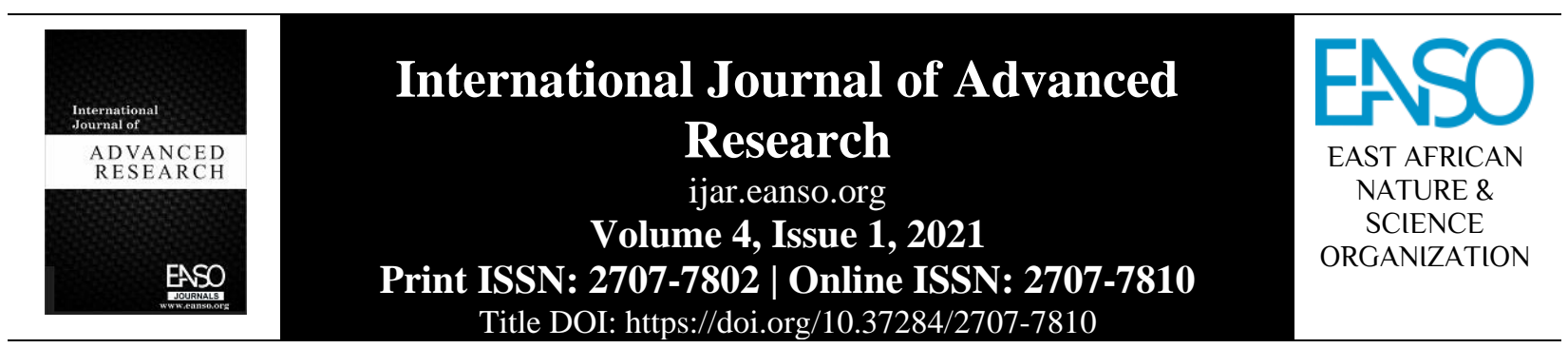

Original Article

\title{
Blockchain Technologies: Potential Use of Cryptographic Protocol in Financing Forests Conservation Stewardship.
}

\author{
Andrew Rutto Kiptum ${ }^{1}$ * \\ ${ }^{1}$ University of Eldoret, P. O. BOX 1125-30100, Eldoret, Kenya. \\ * ORCID: https://orcid.org/0000-0003-3603-0394; Author email: kiptumandrew@gmail.com.
}

Article DOI: https://doi.org/10.37284/ijar.4.1.491

\section{Publication Date: ABSTRACT}

04 December 2021 Environmental markets that consider trade-offs of benefits flow and conservation burdens among economic units contributes to the sustainability of natural resource

Keywords: capital. Despite the benefits of environmental markets, the existence of Technologies, bureaucratic processes in ecosystem financing such as Payment for Environmental Transparency, Services creates a perverse market structure, which impedes the efforts of Trustworthiness, rewards and burdens among economic units. Therefore, this paper explores the
Tradion

Trade-offs, applicability of using cryptographic protocols in blockchain technologies as a Environmental paradigm shift in financing conservation stewardship at the micro-level. Markets. Secondary data from documented literature was used as the source of information in this study. Systematic searches on different websites were used to identify relevant scientific papers, journals, abstracts, reports and presentations that resonated with the theme of this study. To gain hands-on information regarding blockchain technologies, the snowballing research design was used to identify individuals with technological know-how on the functionality and blockchain operability. Blockchain technologies can be merited because it portrays a high degree of transparency and trustworthiness among economic units when used in environmental markets. Therefore, designing a robust cryptographic protocol that facilitates efficient trade-offs of conservation rewards and burdens in present environmental market creates incentives for the resource conservation and protection.

\section{APA CITATION}

Kiptum, A. R. (2021). Blockchain Technologies: Potential Use of Cryptographic Protocol in Financing Forests Conservation Stewardship. International Journal of Advanced Research, 4(1), 1-13. https://doi.org/10.37284/ijar.4.1.491

\section{CHICAGO CITATION}

Kiptum, Andrew Rutto. 2021. "Blockchain Technologies: Potential Use of Cryptographic Protocol in Financing Forests Conservation Stewardship”. International Journal of Advanced Research 4 (1), 1-13. https://doi.org/10.37284/ijar.4.1.491.

\footnotetext{
1 | This work is licensed under a Creative Commons Attribution 4.0 International License.
} 


\section{HARVARD CITATION}

Kiptum, A. R. (2021) "Blockchain Technologies: Potential Use of Cryptographic Protocol in Financing Forests Conservation Stewardship”, International Journal of Advanced Research, 4(1), pp. 1-13. doi: 10.37284/ijar.4.1.491.

\section{IEEE CITATION}

A. R. Kiptum, "Blockchain Technologies: Potential Use of Cryptographic Protocol in Financing Forests Conservation Stewardship", IJAR, vol. 3, no. 1, pp. 1-13, Dec. 2021.

\section{MLA CITATION}

Kiptum, Andrew Rutto. "Blockchain Technologies: Potential Use of Cryptographic Protocol in Financing Forests Conservation Stewardship". International Journal of Advanced Research, Vol. 4, no. 1, Dec. 2021, pp. 1-13, doi:10.37284/ijar.4.1.491.

\section{INTRODUCTION}

The environment in its natural state provides society with ecological attributes that are crucial in supporting human life on earth. The ecological functions of environment that are critical to human survival on earth includes biodiversity conservation, water provision and purification, soil quality maintenance for food production, climate stabilisation, natural disaster abatement, i.e., flood and landslide and so on (Milder et al., 2010). Despite its immense economic contribution, studies by Kiptum et al. (2012) and Kelemen et al. (2016) found natural environments to be facing the pressure of degradation from human activities, which result in disruption of ecosystem functions. For instance, when deforestation occurs, the forest cover is reduced. As a result, the earth loses its thermostats where extreme weather events occur because the ability of forests to sequester heattrapping gases is depleted. Therefore, receding underground water volume in wells and general scarcity of surface water run-off could be associated with unsustainable forest utilisation. Hence, climatic variability could act as environmental signals (Kiptum \& Sang, 2017).

Forests ecosystem functions are public good because its amenities are accessed and consumed freely by immediate, adjacent and far living communities to the environmental resources. Hence, a free-riding syndrome exhibited by forest stock flows services to rural folk is blamed for motivating various economic units to overexploit and degrade environmental resources (Rideout et al., 2013; Kerr et al., 2014). Therefore, continuous extraction of natural resources without distributing impacts that internalise the conservation costs could result into sub-optimal benefit flow among economic units; a deviation of Kaldor-Hicks efficient compensation tests on resources distribution. As pointed out by Lloyd-Smith (2018), conservation of resource that conforms to KaldorHicks compensation tests should exhibit Paretoimprovement, where consumers of environmental products need to pay for the cost incurred by the environmental provider were both economic units ought to remain better off without making themselves worse-off. This is the fundamental theoretical foundation that guides the formulation of policies that maximise the significance of benefits and conservation costs burden between resource consumer and provider, respectively. However, environmental economists view market failures to occur when environmental services are supplied to the economic units for free.

The lexicographic ordering effects that are exhibited by environmental services complicate the management of natural resources. That's the pricing of natural capital is viewed by contemporary economists and society as too abstract. Hence, when the community fails to understand the economic value of environmental services, conservation efforts may be stymied by low weight consideration in policy making, which further stifle decision making by the society in regard to conservation. That's pseudo and/or low pricing of environmental functions brings research gap because it makes the community view natural resource attributes as a gift of nature, making conservation and protection of natural resources capital to be ranked lowly by the community and society.

Fortunately, global awareness and concerns over the reduced environmental products due to overexploitation and degradation are driving innovation in resource conservation. For instance, payment schemes that bring welfare effect or incentivise land users and/or community to conserve the environment have gained traction in 
awareness whenever business, public sector agencies and non-profit organisation come to address environmental issues; however, financing environmental supplier is always a challenge (Pagiola, 2009; Pant et al., 2012). The study by Barbier et al. (2011) found the use of economic incentives where resource consumer is charged to rewards resources supply remains to be a promising set of economic tools that can achieve sustainable conservation efforts.

According to Stavins et al. (2003), the conventional definition of welfare improvement from optimal maximisation of a resource, which explicitly describes the notion of choice of consumption paths and dynamic efficiency, can be expressed from the following analysis:

That's:

$W(t)=\int_{0}^{\infty} U[C(x)] e^{-r(x-t)} d x \ldots \ldots \ldots[1]$

In context to this study, "welfare" $\mathrm{W}(\mathrm{t})$ is an act of maximising resources by household overall feasible consumable paths from land utilities which include rewards or compensation in the conservation realm, which could be defined in utility function as $C(x)$, $\mathrm{U}[\mathrm{C}(\mathrm{x})], \mathrm{t}$ is a specific time period and $\mathrm{r}$ is the rate of income saving. The ultimate outcome over time from relationships in equation (1) will be:

$\frac{W(t)}{d x} \geq 0$

Hence, equation 2 defines resultant household welfare improvement from resource maximisation from equation 1, provided that sustainable income from resource utilisation exhibit efficiency and nondeclining economic benefits streams over time (Stavins et al., 2003). Therefore, using efficient means of financing conservation stewardship brings positive welfare to populations in the realm of income savings could depict Kaldor-Hicks compensation tests.

Studies of Pagiola (2009), Carius (2012) and Kerr et al. (2014) pointed out various challenges that impede the implementation of conservation tradeoffs. These include an inefficient payment process to environmental provider resulting in the collapse of conservation programs at a nascent stage. The study by Pagiola (2009) found that the majority of conservation programs that intends to use economic instruments such as payment for environmental services are formulated without considering the local reality, which makes the community to view the program with mischief. While the study of Carius (2012) and Kerr et al. (2014) found transaction processes in payment schemes to exhibit bureaucratic processes where it passes various proxies. Mischievous perceived programs by local community could also lowers the truth about the money transfer for conservation process.

Therefore, presences of opaque pricing of ecosystem functions coupled with the existence of bureaucratic process in existing environmental markets often create perverse market structures resulting in ineffective reallocation and redistribution of conservation gains. When there is inefficiency in resource sharing, it culminates into conservation apathy among resource providers (Shackleton et al., 2007; Engel et al., 2008; Wunder, 2008). When there is a distorted and/or unclear market transaction, for instance, in payment for environmental services, such trading could collapse, which makes conservation efforts to be zero. The study by Carius (2012) found most of the payment schemes for conservation programs survive for a short period because they rely on short term financing. Therefore, these untruthful and bureaucratic payment processes create financing gaps in market-based conservation programs.

The processes of rewarding environmental providers in environmental markets are often mired by bureaucracy, untruthful and mischief, which is a disincentive in the realisation of environmental resources protection and conservation (Vatn et al., 2009). Despite such difficulties, payment for environmental services is increasingly considered suitable economic instruments to maintain ecosystem functions and services by rewarding environmental providers (Engel et al., 2008; Wunder, 2008; Vatn et al., 2009). Therefore, the innovation of cryptographic roots in blockchain technologies and its potential use in financing various verticals could be a paradigm shift in environmental conservation. The use of blockchain technologies concept is to enhance transaction operability from the user to the recipient in real-time and temper proof process (Boucher et al., 2017; Narayanan, 2015). Operability of blockchain 
technologies in recent financial services, more so in commerce, is a built-in context to the single version of the truth by providing transparency for historical and real-time business transactions. Based on this merit, blockchain technology is gaining prominence in some regions of the globe, while in other countries, it is being used at a piecemeal pace because of its legislative challenges, difficulty in understanding its functionality and opaqueness in its operability (Narayanan, 2015) (see Figure 1). The rapid wave of interest around blockchain technologies globally is supported by a proof of work consensus mechanism authenticated by the public network from decentralisation which raises truthful platform in money transactions among an ecosystem of traders (Narayanan, 2015; Cermeno, 2016).

Figure 1: Attitude of countries that have adopted the use of cryptocurrency

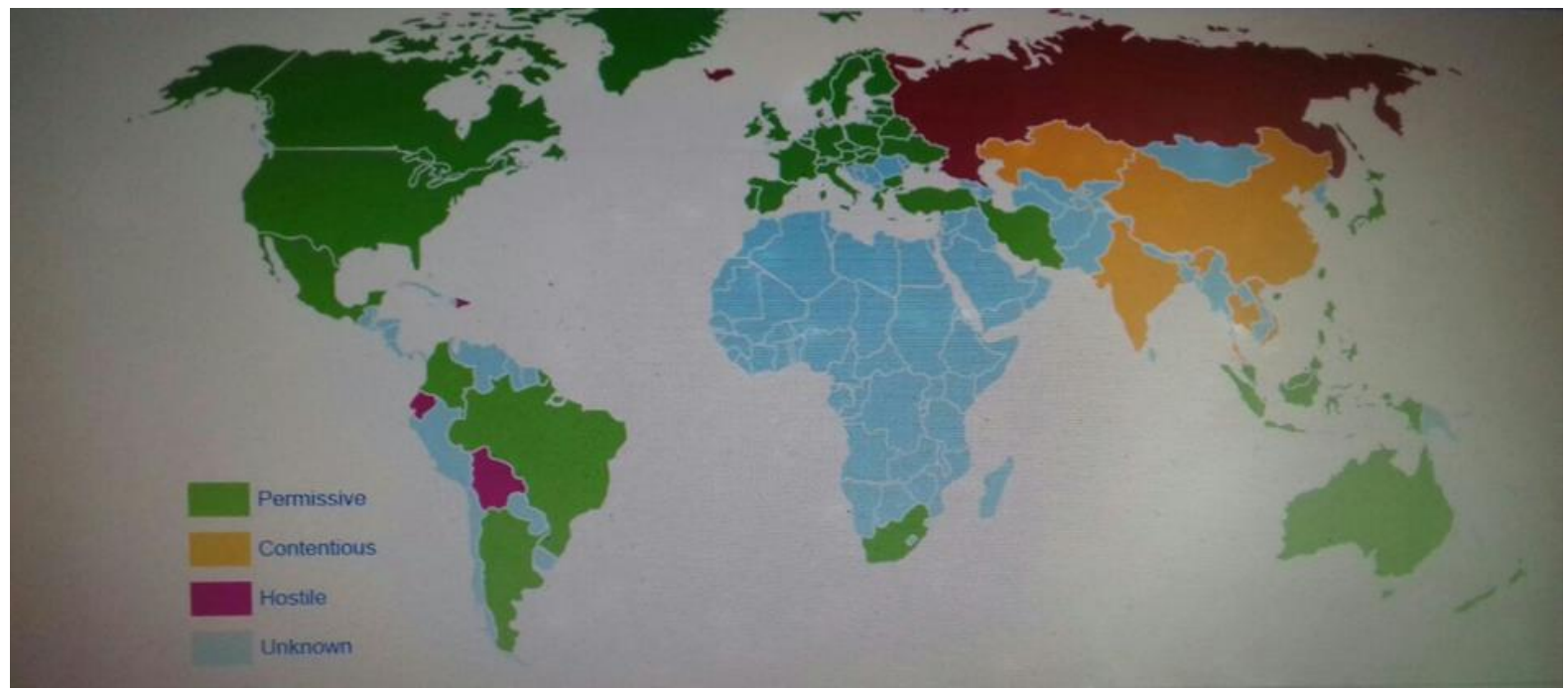

Source: Bitlegal.io

Payment through cryptographic roots is merited because of intrinsic benefits such as the instant settlement of debts, easier, and more trustworthy management of debt attached with collateral. The capability of stakeholders in monitoring financial transactions, which is often invisible in contemporary financial networks, elimination of clearing agents which reduce financial bureaucracies and effective and efficient globalised financing is enhanced by cryptographic roots (Cermeno, 2016; Carius, 2012; Mattila et al., 2016). Therefore, for this technology to efficiently work, then, software programs need to be developed which basically downstream instruction in a coded form, such as reference condition for payment is uploaded (Cermeno, 2016; Boucher et al., 2017). Hence, operability of the open-source cryptographic protocol in blockchain technologies is merited because it could allow various environmental conservation stakeholders to validate every financial transaction in environmental markets through consensus mechanisms, which allows trading of ecosystem services among economic units amicably.

\section{CONTEXT AND METHODS OF REVIEW}

\section{Methods of Information Seeking}

To address the research's objective, we reviewed various literature that resonates on financing services, specifically on the applicability and operability of blockchain technologies in easing the payment process systematic searches on different websites, i.e., the ISI Web of Knowledge (WoK) (http://wok.mimas.ac.uk/), which is among the world's largest databases of scientific papers, were used to identify relevant scientific papers, abstracts, journals, reports and presentation. While seeking secondary data and information from the web, a systematic review was used (Pullin \& Stewart, 2006). The guiding search terms used were

$4 \mid$ This work is licensed under a Creative Commons Attribution 4.0 International License. 
'Environmental service fund,' 'payment for environmental services (PES),' 'Blockchain technologies,' and 'crypto-currency,' along with other relevant terms that describe blockchain technologies.

Despite its rudimentary and/or low applicability of blockchain technologies in financial transactions in businesses and commodity transaction systems globally, snowballing research design in this study was used by targeting individuals with hands-on knowledge on the operability, especially in cryptocurrency such as Bitcoins. In reviewing secondary data, we focused on the merit that comes when blockchain technologies are being used and practical challenges that are associated with these financing approaches.

Linking Blockchain Technologies, Financing Services and Conservation Stewardship
There is growing awareness of the importance and values of forest products and their ecosystem functions in improving the economic well-being of the population (Shackleton et al., 2007) and appreciation for conservation stewardship by resource users (Ruhweza et al., 2008; Milder et al., 2010). When economic contribution by resource users either in monetary or in-kind is transferred efficiently through trustworthy means, it will provide necessary incentives for households to initiate and/or upscale conservation stewardship.

Trees planted in woodlot have been found to be the popular tradable conservation stewardship in most of the established environmental markets (Ruhweza et al., 2008). The study by Pagiola (2009) suggested environmental assets such as trees in woodlot be possibly used as collateral in accessing credits or in developing pseudo insurance schemes because its ecosystem services attributes such as sustained underground water reservoir have immense benefits to adjacent.

Figure 2: Schematic diagram of a typical transactions flow in blockchain technologies community and the population living far beyond tree stands

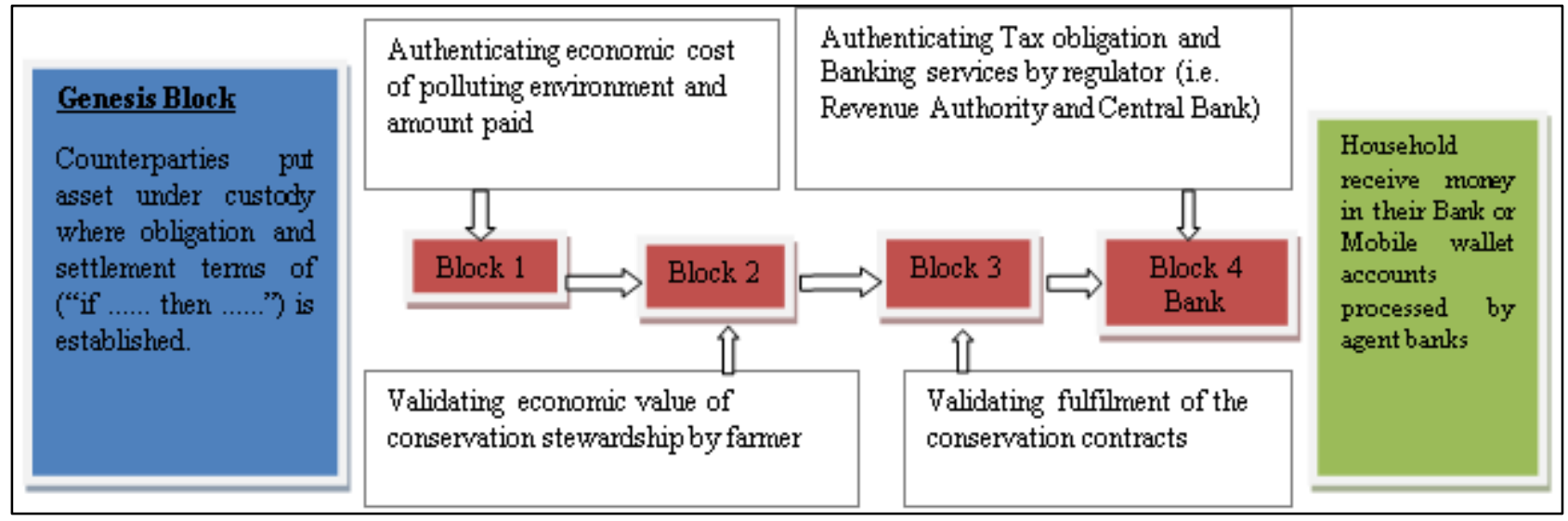

A case study (see Box 1) depicts expressed willingness by households to allocate land for trees which opens the nexus of financing conservation stewardship through blockchain technologies. Based on that, bequeathed trees provided the collateral value of trees in a stand is determined, can be integrated and implemented as economic assets by financing its conservation and protection using blockchain technologies.
The functionality of Blockchain Technologies

Blockchain(s) technologies are made up of several blocks and each block contains coded deliverables where hundreds of transactions are executed. Depending on the objectives of verticals, each block contains baseline conditions which are often referred to as 'smart contracts.' These contracts are formulated to trigger the execution of financial transactions (Boucher et al., 2017). Figure 2 depicts a series of blocks $1,2,3$, and 4 , which display the usual way of thinking about how blockchain

5 | This work is licensed under a Creative Commons Attribution 4.0 International License. 
technologies operate. The genesis block (Blue) in Figure 2 is the start of transactions where counterparties establish obligations and settlement instructions. Terms of contracts dictate the flow of financial transactions in the labelled brown blocks that forms the main chain. However, the application of blockchain technologies differs in each case to the case where its utilisation leverage a diverse range of benefits on different verticals such as trade finance, automated compliance, global payments and asset re-hypothecation (i.e., payment schemes for environmental service). Empirical evidence depicted in Box I reveals the willingness of several households to bequeath conservation stewardship for future generations.

Box 1: A case study depicting the significance of transparency through community participation in community environmental conservation stewardship projects.

\section{Introduction}

Existences of forests provide society with ecological services which are crucial for human livelihood. Status of public forests cover in Uasin Gishu, Kenya as a study area have been degraded due to overconsumption from ever increasing population which distorts the nexus of ecosystem services and livelihood (Oyugi, 2015). However, lack of transparency and accountability, embezzlement of funds, and existences of bureaucracies in management of community projects by resources managers could discourages resources providers to engage into conservation stewardship. This creates a complex puzzle that needs efforts that could incorporate resources supplier in decision making as a way of enhancing sustainability of forests and its resources. In the study, a resource supplier ought to participate in conservation decision making was tested. This necessitated determination of its influence regarding participation and aspiration in conservation contribution. To achieve influencing levels, comparison of expressed willingness to contribute for community conservation projects by rural households was made between two scenarios were existences and/or inexistence of democratically elected representative of rural community in decision making for the management of the expressed pooled fund for conservation activities.

\section{Methodology and Information Sought}

While administering questionnaires for primary data collection, systematic random sampling was employed in selecting rural household as target population. Two hypothetical questions was formulated in the questionnaire; with the first question asking respondents to express the amount they were willing to contribute for the pooled fund in aid of community conservation activities. While, the second question asked respondents to state an additional amount if democratically elected representative of the community were involved in management of the pooled fund and in decision making in regards to community conservation activities.

\section{Results and Implication}

From the result, the average expressed contribution was $\$ 5.84$ when representative from community was involve in management and decision making which increased from \$3.65; a marginal increase of $\$ 2.21$ or a proportion of about $61 \%$. The marginal increase of expressed willingness value for community conservation projects when community participation were involved in decision making and management, indicates the significance of developing participatory approach that enhances transparency and truthful platforms. Juxtaposing this finding with environmental markets in regard to economic transactions platforms among economic units, then, cryptographic protocol in blockchain could act as incentive that encourage household to upscale conservation efforts. As such, a blockchain technology that uses cryptographic protocol could offers transparency and truthful platforms provided "smart" contracts between resources producer and consumer are developed.

Source: From Unpublished Thesis (Kiptum R. Andrew)

Ecological functions from trees in woodlot tend to offer stock-flow benefits such as underground water flow and retention; significant services that guarantee sustainable surface water flow to in-situ and ex-situ population (Kiptum \& Sang, 2017).

6 | This work is licensed under a Creative Commons Attribution 4.0 International License. 
However, the protection and maintenances of these trees comes with a cost that often remains unaccounted for. Studies by Pagiola (2009) and Ruhweza et al. (2008) found ecosystem function of trees in woodlot form could easily be valued using a mix of ecosystem valuation approaches such as opportunity costs, surrogate and/or revealed the market price of tree products. Determined economic value from trees in stands can be used to trade ecosystem services in established environmental markets among local, regional and global economic units. Providing economic incentives to households that have expressed their willingness to conserve the ecosystem could resolve the environmental challenge of reduced forest products and services supply arising from dwindling forest cover. The most impactful financial services are the one that can be quickly implemented and offers single truth during transactions processes; as such, blockchain technologies fits this preposition (Carius, 2012). That's blockchain(s) have universal shared sources of information where information could be stored in a tamper-proof way, creating a single version of the truth.

Ideally, the execution of any payment processes in blockchain technologies shouldn't happen or be modified without transacting stakeholders' notice. According to McWaters (2016), while describing the simplest settings in blockchain technologies, several stakeholders that are involved in transacting processes are made to share the same log-in key $k$ and use in encrypting and decrypting contract information. This means that a random string of $k$ bits is uniformly distributed among stakeholders for some parameters $\left(k_{1 \ldots n}\right)$. Stakeholder in the $1^{\text {st }}$ block (Figure 2) can apply an encryption algorithm based on fulfilled contracts condition on conservation by resource providers which are households, i.e., planted right species of trees on the specified soil type, agro-ecological conditions, distance to watershed, and acreage and so on, which can be specified as $x$ conditions under the key $k$ to get cipher transaction function $\mathrm{C}$. The resultant cipher transaction function $\mathrm{C}$ is the code sent to subsequent stakeholders for authentication and validation, which makes it to remain a single version of truth on the payment process among transacting stakeholders.
When the recipient stakeholder gets cipher transaction function $\mathrm{C}$, he applies the corresponding decryption algorithm to recover the send reference conditions that form smart contracts $x$ which triggers fulfilment or payment processes for contracts. Therefore, this is the symmetric encryption settings of financial processes invoked by the ecosystem of stakeholders using shared login $k$ in cryptographic blockchain.

However, a fresh number is required from each time the encryption algorithm is invoked in the subsequent chains of blocks. This implies that the invoked encrypted algorithm twice with the same parameter $x$ using uniformly distributed $\log$-in $k$, will produce a different cipher transaction function C. The following relationship can be expressed in a functional equation form as:

$C=f_{0}(k, x) \ldots \ldots \ldots[3]$

Where authenticating and validation of conservation contracts i.e., allocated land by household for specific tree species in conformity to conservation contracts $x$, is applied with encrypted algorithm by $1^{\text {st }}$ stakeholder using the shared log-in key $k$ to produce a different cipher transaction function $\mathrm{C}$. The resultant cipher transaction function $\mathrm{C}$ is sent to the subsequent chains of blocks for other authorised stakeholders to validate financial transaction processes.

Stakeholder who receives the send cipher transaction $\mathrm{C}$ would apply the decryption algorithm to recover conservation contracts to allow him/her to authenticate and validate financial processes in blockchain technologies.

That's: $x=f_{i}(k, C \ldots \ldots \ldots \ldots \ldots \ldots . . . \ldots[4]$

The resultant function from the decryption algorithm will yield a different function (equation 4) which would be used to encrypt the algorithm by $2^{\text {nd }}$ stakeholder and send it to the $3^{\text {rd }}$ stakeholder for further financial processes after validating conservation contracts $x$.

\section{Stakeholders Ecosystem}

Technology by principle cannot be regulated, but activities performed using those technologies are regulated. Market participants (ecosystem

7 | This work is licensed under a Creative Commons Attribution 4.0 International License. 
stakeholders) in blockchain technology depend on the verticals because different verticals contain unique contracts and thus stakeholders. Market transactions in the blockchain is authenticated by respective market participants who are diverse and specific in each block depending on inbuilt 'smart contracts' and their roles in the verification process in that specific vertical. Possible stakeholder's ecosystem that can be involved in authentication process in context to this study, though not limited to the mentioned ones in Table 1.

Figure 3: Depiction of cryptographic roots and stakeholder's interaction in ecosystem financing process

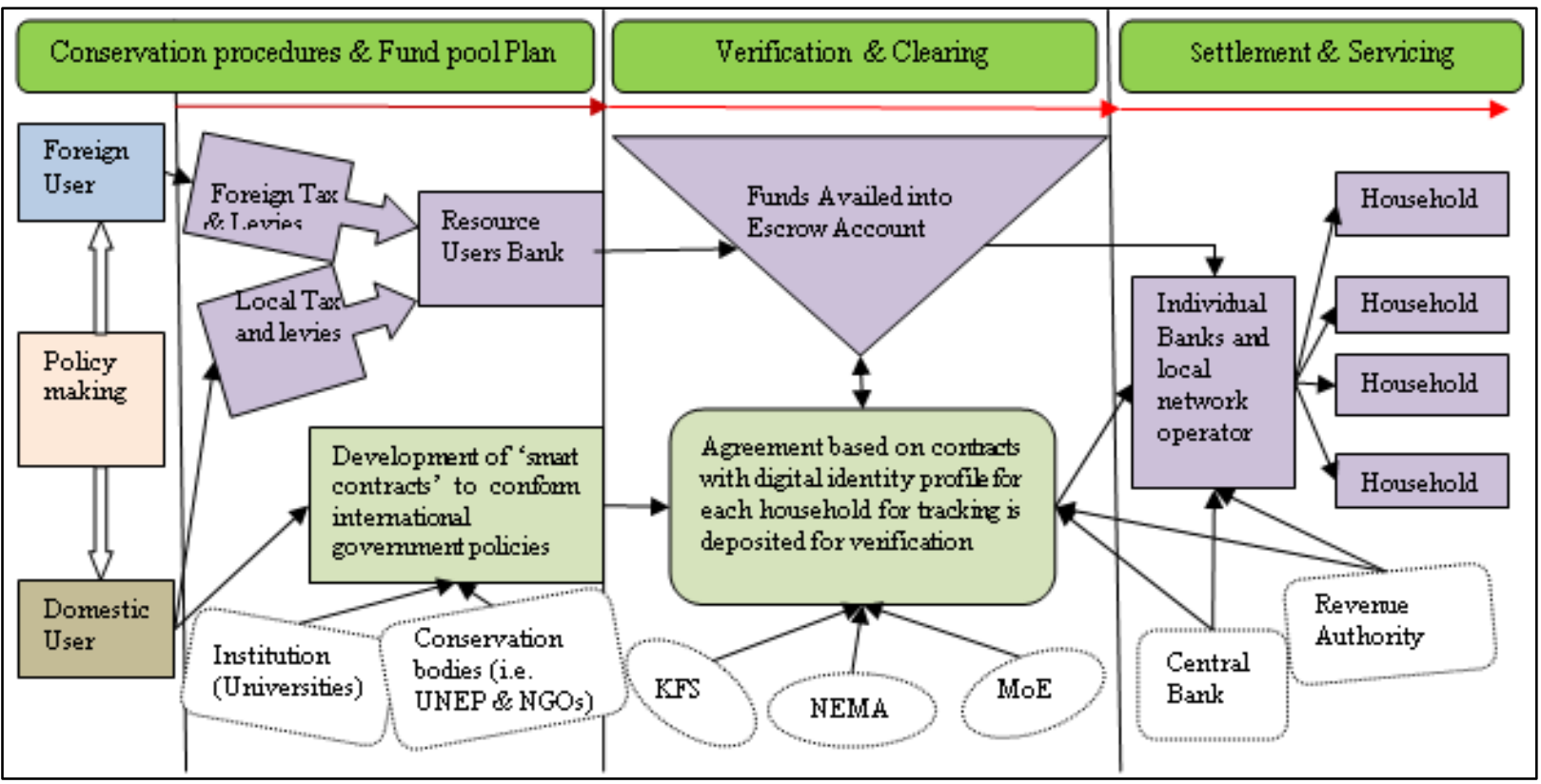

- Households or Beneficiary. Efforts of conservation emanate from household activities such as the adoption of energy-saving methods, tree planting, and soil erosion control and so on. Households are critical stakeholders who take centre stage in environmental management (Keenan et al., 2015; Kelemen et al., 2016). Therefore, motivating them through designed payment schemes that incentivise them to practices conservation is critical for sustainable ecosystem services provisions. Therefore, its position in the blockchain is critical in the development and adoption of smart contracts. Fulfilment of the set contracts could mean conservation stewardship has been made which triggers the payment process in blockchain technology.

- Resource users. Environmental services are global good which is consumed beyond national territory. Some resource users consume environmental products without bearing any cost; yet, environmental providers incur costs in maintaining ecosystem services. Local and foreign resource users include Water Service Boards, Carbon emitters (i.e., automobile), Irrigation firms and Manufacturers/industries that produce trap-heating gases etc. Levies and taxes can be imposed to products that emit carbon or heat-trapping gases, institutions that use environmental products or environmental products such as water service boards and sawmillers, where such funds can be used to reward household who offers conservation stewardship for free. Funds from philanthropists and institutions through corporate social responsibility can form part of rewards to environmental providers.

- Policymakers and research institutions. Policy formulation that obligates polluters to pay for their pollution could play a critical role in

$8 \mid$ This work is licensed under a Creative Commons Attribution 4.0 International License. 
mobilising compensation fund. Policies could emanate from governments and research institutions. Policymaking institutions that can be incorporated in context to the Kenyan case are the National Environmental and Management Authority, Ministry of Environment, Universities and Treasury who are responsible for imposing monetary policies to polluting products that disrupt ecosystem functions.

Auxiliary institutions that have mandates of managing natural resources such as the ministry of agriculture, water and irrigation and the National Land Commission could also be incorporated as supportive stakeholders. Other institutions whose services are critical and their roles are supportive in blockchain technologies include the banking industry and network providers. Activities of service providers such as telecommunication firms, local banks and international banks need to be regulated by concerned authorities to curb mischief arising during the financing process.

- Regulators. Regulators play critical roles by streamlining noncompliance and inappropriate money transfer activities in the environmental market. Regulator raises the information truth in the transaction activities. However, transactions and regulators vary in each block due to the different roles actors do perform. For instance, regulations of banks by Central Bank on levies and taxes remittance imposed to polluters can too be regulated by Revenue Authorities.

Table 1: Tentative stakeholder ecosystem that can be involved in regulating ecosystem services financing in cryptographic roots

\begin{tabular}{|c|c|c|}
\hline Market Participants & Status & Description and Role \\
\hline $\begin{array}{l}\text { Money } \\
\text { Sender/resource user }\end{array}$ & Core & $\begin{array}{l}\text { Individual or business entity charged to pay for conservation } \\
\text { through polluter pays principle }\end{array}$ \\
\hline Beneficiary & Core & $\begin{array}{l}\text { Resource supplier who bear the cost of conserving environment } \\
\text { i.e. by planting trees, and need to be rewarded for conservation } \\
\text { stewardship. }\end{array}$ \\
\hline Beneficiary Bank & Core & A bank used by beneficiary to receive funds \\
\hline $\begin{array}{ll}\text { Money } & \text { Transfer } \\
\text { Operator } & \\
\end{array}$ & Core & $\begin{array}{l}\text { Bank and Non bank entities that are specialised in money } \\
\text { transfer in both local and international through network. }\end{array}$ \\
\hline Policy makers & Core & $\begin{array}{l}\text { Authorities who make policies and affect to facilities fund } \\
\text { accumulation through compulsory payment for environment } \\
\text { schemes through polluter pays principles }\end{array}$ \\
\hline Correspondent Bank & Supporting & $\begin{array}{l}\text { These are banks that have ability to facilitate payment processes } \\
\text { from foreign bank to local banks. }\end{array}$ \\
\hline $\begin{array}{ll}\text { Local } & \text { Clearing } \\
\text { Network } & \\
\end{array}$ & Supporting & $\begin{array}{l}\text { The national interbank network that allows financial messaging } \\
\text { and financial settlement services }\end{array}$ \\
\hline Financial Regulator & Supporting & $\begin{array}{l}\text { Authorities that determine and monitor the adherence of } \\
\text { financial discipline on bank, consumer protection and settlement } \\
\text { of smart contracts. }\end{array}$ \\
\hline Institutions & Supporting & $\begin{array}{l}\text { These are institutions that have the capabilities of giving } \\
\text { technical know-how on financial services in blockchain } \\
\text { technologies. Their technical input can nature and improve the } \\
\text { operability and applicability of blockchain to higher frontier. }\end{array}$ \\
\hline
\end{tabular}

Note: Environmental provisions are a global phenomenon which requires expanded market participants in blockchain technologies. The need for diverse participants is to gather for local and international

9 | This work is licensed under a Creative Commons Attribution 4.0 International License. 


\section{DISCUSSION ON REAL-TIME INTERACTIONS OF BLOCKCHAIN TECHNOLOGIES}

The significances of having data and information in a shared digital platform in almost real-time could allow transacting partners to regulate and monitor financial processes (McWaters, 2016; Matilla et al., 2016). For this to happen, sets of tamper-proof 'smart contracts' need to be registered in digital format for stakeholders to verify and authenticate transactions activities (Boucher et al. 2017), which creates a single version of truth (Carius, 2012; McWaters, 2016). Smart contracts in blockchain technologies are programmed platforms that generate payment instructions for downstream stakeholders to authenticate and validate financial transactions if reference conditions in the contract are met (Matilla et al., 2016). Once conditions in the contracts are validated and accepted by counterparties, the transactions which are unidirectional become immutable (Carius, 2012; McWaters, 2016).

Engagement of the ecosystem of stakeholders in a cryptographic root is illustrated in Figure 3 where several real-time transactions in blocks are executed. In context to financing environmental services, often the consumption of ecosystem services freely while adjacent community bear the cost in conserving environment, which creates perverse market structure. As such, scaling funds sources through policies on local users and beyond is necessary to contribute to conserving the environment. Developing policies that tend to mobilise resources to fund conservation stewardship could be the first step in designing financing protocol in blockchain technologies.

To explicate transaction activities in Figure 3, government through national treasury can develop fiscal and monetary policies that aim to collect funds from resource users. These policies can be developed jointly with various institutions in order to give impetus. Although actual Pareto improvements are exceptionally rare and perhaps even non-existent (Stavins, 2002), however, proposed policies should pass the Kaldor-Hicks compensation test, where the actual compensation of losers by winners should exhibit strict Pareto criterion. The institution that can take part in formulating conservation policies are local (i.e., research institutions, universities, private entities and government departments) and international bodies such as UNEP, World Bank and NonGovernment Organisations. Thereafter, counterparties can develop obligation and settlement agreements that conform to environmental conservation policies.

Cardinal in developed smart contracts should resonate on improving quality and quantity of ecosystem services flow. For instance, in the context of tree farming, tree species planted by household, agro-ecological conditions of the land, and distance to water sources should be conditions that should be considered as determinants that trigger contracts. This is because distances of biophysical factors such as forests significantly influence underground water retention (Kiptum and Sang, 2017). Therefore, nexus between distance of trees planted and watershed is necessary to be included while developing smart contract that triggers payment for conservation stewardship.

Once obligations and settlement contracts have been developed, it is then uploaded as digital ledgers to allow verification of conditions by respective stakeholders if such conditions have been met by the household to warrant payment. Verification and validation processes in each transaction are immutable once validated (see Figure 3). Therefore, the transfer of money from a pool fund account (escrow account) to the household bank account and/or mobile wallet facilitated by network operators cannot be mutated. This raises transparency, trustworthiness and participation in financial transactions processes because of involves of all stakeholders, which is a key incentive for the realisation of natural resource conservation.

\section{CONCLUSION}

Financing ecosystem services in the established environmental markets are increasingly considered a suitable economic instrument that incentivises conservation stewardship at the micro level to maintain continuous flow of ecosystem services to the population. However, the payment process is mired by opaque transactions due to proxies that are involved in the financial transactions. An effectively and efficient financial service that 
facilitates easy transfer of welfare gains to environmental suppliers could correct the nexus characterised by perverse markets that are associated with inefficient payment processes. It is important to consider how much welfare gains and losses are distributed among economic units: who gains, who loses and by how much? Therefore, effective and efficient transfers of rewards in environmental markets with the aim to improve ecosystem services flow could incentivise households to upscale conservation practices such as tree farming, soil erosion control, biodiversity conservation and adoption of energy-saving methods.

Although facilitation through distribution of conservation rewards regarding provider gets principle and/or polluter pays principles which is a major concern in sustainable forests and/or natural resource conservation realm, however, in this paper we tried to show the applicability of blockchain technologies as a solution in facilitating efficient transfer of rewards for ecosystem provision as incentives. Despite the use of blockchain technologies in financial services being at its nascent stage, its interest and awareness is gaining traction due to its significant benefits of enhancing efficient financial services.

Characteristics that merit blockchain technologies are the secured transactions with cryptographic hashes which offer temper-proof transaction processes based on proof-of-work consensus mechanisms by stakeholders. It also allows records to be created and verified with a greater level of speed, security and transparency since all data and information are in encryption format and can be accessed by authorised stakeholders in real-time scenarios and it allows flexibility of developing diverse odds which acts as diverse markets to be bided. These make blockchain technologies to be more acceptable in financial services because gives more democracy in financial transactions and thus incentivise resource owners to trade-off tradable commodities such as conservation efforts in environmental markets. Despite possibly wide applications in financing services, however, the use of blockchain technologies is bulked by the inexistence of enforceable legal framework and regulation. Therefore, it calls for a proportionate formulation of regulatory approaches and the development of appropriate capacity building and expertise on case-by-case cryptographic roots in order to gain its full benefits.

\section{ACKNOWLEDGEMENTS}

The authors thank respondents who participated in giving valuable views in regard to the possible applicability of Blockchain technologies in financial services.

\section{REFERENCES}

Barbier, E. B., Hacker, S. D., Kennedy, C., Koch, E. W., Stier, A. C., \& Silliman, B. R. (2011). The value of estuarine and coastal ecosystem services. Ecological monographs, 81(2), 169193.

Boucher, P., Nascimento, S. \& Kritikos, M. (2017). How blockchain technology could change our lives: In-depth analysis. Brussels: European Parliamentary Research Services

Carius, F. (Eds). (2012). Payment for Environmental Services: Towards an Implementation Strategy Report of the International Expert Workshop $13^{\text {th }}-16^{\text {th }}$ December 2010. International Academy for Nature Conservancy Isle of Vilm, Germany.

Cermeño, J. S. (2016). Blockchain in financial services: Regulatory landscape and future challenges for its commercial application. Working Paper No. 16/20. Madrid, Spain: BBVA Research.

Engel, S., Pagiola, S., \& Wunder, S. (2008). Designing payments for environmental services in theory and practice: An overview of the issues. Ecological economics, 65(4), 663-674.

Keenan, R. J., Reams, G. A., Achard, F., de Freitas, J. V., Grainger, A., \& Lindquist, E. (2015). Dynamics of global forest area: Results from the FAO Global Forest Resources Assessment 2015. Forest Ecology and Management, 352, 920.

Kelemen, E., García-Llorente, M., Pataki, G., Martín-López, B., \& Gómez-Baggethun, E. (2016). Non-monetary techniques for the 
valuation of ecosystem services. In: PotschinYoung, M. \& Jax, K. (eds), OpenNess Ecosystem Services Reference Book. Operationalisation Of Natural Capital And Ecosystem Services (OpenNESS).

Kerr, J., Vardhan, M., \& Jindal, R. (2014). Incentives, conditionality and collective action in payment for environmental services. International Journal of the Commons, 8(2), 595-616.

Kiptum, A. R., \& Sang, C. C. (2017). Determinants of groundwater retention in wells: A case of Keiyo North district, Elgeyo Marakwet County, Kenya. Journal of Water Security, 3, 1-7.

Kiptum, A., \& Sang, C. (2018). Ground Water Level Variability and their Cost Implications: A Case of Keiyo North Sub-County, Elgeyo Marakwet County, Kenya. Africa Environmental Review Journal, 2(2), 46-54.

Kiptum, A., Kipkoech, A., Adano, W. R., Osano, O., Biryahwaho, B., \& Agasha, A. (2012). Impacts of community activities on environmental resources: the potential for developing payment schemes for environmental services. In Kipkoech, A., Okeyo-Owuor, J. B. \& Mogaka, H., Towards Implementation of Payment for Environmental Services (PES): A collection of findings linked to the ASARECA funded research activities (pp. 290-300). VDM Verlag Dr. Müller, Germany.

Lloyd-Smith, P. (2018). A Note on the Robustness of Aggregate Ecosystem Service Values. Ecological Economics, 146, 778-780.

Mattila, J., Seppälä, T., Naucler, C., Stahl, R., Tikkanen, M., Bådenlid, A., \& Seppälä, J. (2016). Industrial blockchain platforms: An exercise in use case development in the energy industry. The Research Institute of the Finnish Economy (ETLA) Working Papers No. 43. The Research Institute of the Finnish Economy.

McWaters, J. (2016). The future of financial infrastructure: An ambitious look at how blockchain can reshape financial services. World Economic Forum.
Milder, J. C., Scherr, S. J., \& Bracer, C. (2010). Trends and future potential of payment for ecosystem services to alleviate rural poverty in developing countries. Ecology and Society, 15(2), 4-11.

Narayanan, A. (2015) Analysing the 2013 Bitcoin fork: centralised decision-making saved the day. Retrived from Freedom to Thinker, https://freedom-totinker.com/2015/07/28/analyzing-the-2013bitcoin-fork-centralized-decision-makingsaved-the-day/

Oyugi, D. (2015). Main Rivers or other Water Bodies. Nairobi, KE: The Nature Conservancy.

Pagiola, S. (2009). Payments for Environmental Services: An Introduction. Washington, DC Environment Department, World Bank.

Pant, K. P., Rasul, G., Chettri, N., Rai, K. R., \& Sharma, E. (2012). Value of forest ecosystem services: a quantitative estimation from the Kangchenjunga landscape in eastern Nepal. ICIMOD Working Paper No. 2012/5. Kathmandu, Nepal: International Centre for Integrated Mountain Development (ICIMOD).

Pullin, A. S., \& Stewart, G. B. (2006). Guidelines for systematic review in conservation and environmental management. Conservation biology, 20(6), 1647-1656.

Rideout, A. J., Joshi, N. P., Viergever, K. M., Huxham, M., \& Briers, R. A. (2013). Making predictions of mangrove deforestation: a comparison of two methods in Kenya. Global change biology, 19(11), 3493-3501.

Ruhweza, A., Biryahwayo, B. \& Kalanzi, C. (2008). Inventory for Payments for Ecosystem Services in Uganda 2008. East and Southern Africa Pes Review Inventory Matrix on PES in UgandaDRAFT. https://www.forest-trends.org/wpcontent/uploads/imported/2008_Uganda_Invent ory.pdf

Shackleton, C. M., Shackleton, S. E., Buiten, E., \& Bird, N. (2007). The importance of dry woodlands and forests in rural livelihoods and 
poverty alleviation in South Africa. Forest policy and economics, 9(5), 558-577.

Stavins, R. N., Wagner, A. F., \& Wagner, G. (2003). Interpreting sustainability in economic terms: dynamic efficiency plus intergenerational equity. Economics Letters, 79(3), 339-343.

Vatn, A., Vedeld, P., Pétursson, J. G., \& Stenslie, E. (2009). The REDD direction: the potential for reduced forest carbon emissions, biodiversity protection and enhanced development: a desk study with special focus on Tanzania and Uganda. Noragric Report No 51. Department of International Environment and Development Studies, Norwegian University of life Sciences.

Wunder, S. (2008). Payments for environmental services and the poor: concepts and preliminary evidence. Environment and development economics, 279-297.

13 | This work is licensed under a Creative Commons Attribution 4.0 International License. 